\title{
GESTÃO CONFLITIVA DE MEMÓRIAS DOCUMENTAIS PELA UNESCO
}

\section{Hilário Figueiredo Pereira Filho}

E-mail: hilario.pereira@iphan.gov.br

Instituto do Patrimônio Histórico e Artístico Nacional (Iphan), Rio de Janeiro - RJ, Brasil

DOI $10.1590 / 3610509 / 2020$

\section{Introdução}

Criada em meio à crise mundial decorrente de duas grandes guerras, quando as crenças no progresso e na ciência passaram a ser amplamente questionadas, a Organização das Nações Unidas para a Educação, a Ciência e a Cultura (Unesco) surgiu como espécie de armistício no conturbado cenário global de meados do século XX. Esse traço mediador da agência permanece em seu discurso contemporâneo e em sua própria imagem, possibilitando a emergência de representaçóes que a concebem como um organismo capacitado a adotar alternativas e caminhos conciliatórios. Ao se qualificar como a "agência intelectual da ONU" em seu site oficial na internet, a Unesco explicita, sem maiores rodeios, suas pretensóes de assumir o protagonismo nas áreas da educação, ciência e cultura.

Artigo recebido em: 24/09/2019

Aprovado em: 09/03/2020
Este desafio é tamanho que acaba por demandar uma ampla rede de parceiros, entre os seus atuais 195 Estados-membros, cujas ações diversificam-se sobremaneira em diferentes contextos históricos e territoriais.

Pertencente ao conjunto de agências especializadas da Organização das Naçóes Unidas, como o Banco Mundial, o Fundo Monetário Internacional (FMI) e a Organização Mundial da Saúde (OMS), a Unesco integra um sistema complexo, que se estrutura a partir de intricados programas e fundos; contribuiçôes voluntárias dos países e parcerias com entidades do setor privado permitem a implantação de suas iniciativas pelo mundo. A Unesco vincula-se ao Conselho Econômico e Social da ONU, e muitos estudiosos a qualificam como a menos especializada das instituiçôes que compõem o sistema das Naçóes Unidas (Bamouni, 1981, p. 15). Outras críticas costumeiras afirmam que a missão dessa organização internacional é demasiadamente vaga, o que pode 
acabar gerando mal-entendidos e controvérsias para aqueles que se interessam por compreender seu funcionamento (Maurel, 2005, p. 13).

Autônoma em relação à $\mathrm{ONU}$ e dotada de um organograma funcional que atesta a complexidade da sua estrutura, a Unesco estabeleceu diversos trabalhos conjuntos com governos, agências internacionais e organizações não governamentais (ONGs) ao longo de sua trajetória de mais de sete décadas. Tais parcerias aconteceram muito em função do seu orçamento, nem sempre compatível com as tarefas propostas, e de uma autoimagem: a agência se define como "um laboratório de ideias e uma instituição que fixa padróes para tecer consensos universais sobre temas éticos emergentes" (Unesco, 2004, p. 33). A organização esforça-se, portanto, para se apresentar como uma espécie de fórum central, concentrando temáticas que permeiem os domínios nos quais se propóe atuar. A busca obstinada de um suposto entendimento mútuo entre os Estados participantes acaba por cristalizar a imagem da Unesco como uma arena plural, na qual os conflitos entre países poderiam ser dirimidos.

Aliada a essa visão utópica - de ser capaz de neutralizar embates e disputas entre seus Estadosmembros por meio de diálogos nutridos pelos preceitos da educação, da ciência e da cultura -, a Unesco goza da prerrogativa de ser uma organizaçáo multifacetada. Tal pluralismo pode ser, por vezes, simplificado, correndo-se o risco de incorporar acriticamente visôes unívocas e a-históricas. Ao desnaturalizar algumas imagens dessa agência, João Macedo Castro argumenta que é necessário problematizar a Unesco tanto em relação aos Estadosmembros como em sua inserção no sistema da ONU, já que existe um processo permanente que reordena suas estruturas organizacionais: "Não existe uma Unesco, mas Unescos distintas e integradas, operadoras de estratégias internacionais" (Macedo Castro, 2005, p. 95). David Berliner e Chiara Bortolotto lançam a proposta de pensar a Unesco para além da lógica dicotômica global e local; para eles, por trás da marca abstrata da agência há uma série de locais, indivíduos e ações. Calcados na abordagem etnográfica, os autores defendem descriçóes complexas da Unesco a partir de suas práticas institucionais, dinâmica que permite perceber um conjunto de negociaçóes que estão longe de serem homogêneas e consensuais (Berliner \& Bortolotto, 2013, p. 4). Nessa medida, interessa realizar recortes de pesquisa que valorizem a historicidade dos contextos, aliados à noção de que a Unesco não pode ser compreendida como um todo homogêneo e simplificável.

Nosso olhar se volta para o programa Memória do Mundo da Unesco, com atividades iniciadas no começo da década de 1990. Instituído pelo setor de Comunicação e Informação da agência, seu funcionamento ocorre em três níveis hierarquicamente distintos: o internacional, sendo a Secretaria, sediada em Paris, responsável por lançar as diretrizes gerais, a partir das decisóes do Comitê Consultivo Internacional (CCI); o nível regional, respaldado nas cinco divisóes geopolíticas adotadas pela Unesco, com Comitês Regionais que correspondem a três delas (Ásia e Pacífico, África, e América Latina e Caribe); e o nível nacional, com 77 unidades distribuídas entre os Estados-membros. $\mathrm{O}$ aspecto de maior visibilidade do programa consiste no título de patrimônio documental, conferido a acervos documentais e bibliográficos pertencentes a arquivos, bibliotecas e museus. Também denominado de registro e/ou nominação, esse reconhecimento simbólico do MOW ${ }^{1}$ pode ser obtido nos três níveis, gerando uma espécie de sombreamento e redundância dos títulos: "Memória do Mundo Internacional", "Memória do Mundo Regional" e "Memória do Mundo Nacional".

Segundo as diretrizes do programa, a diferença entre as nominaçóes se ancora na perspectiva potencial de influência territorial de determinado acervo. Apesar de ressalvar que todos os registros do Memória do Mundo têm importância mundial, a Unesco aplica ao programa um senso de hierarquia geográfica presente também em outras açôes que capitaneia. Lançamos a hipótese de que alguns candidatos - em sua grande maioria, instituições públicas - veem na alçada do MOW Internacional a forma mais eficaz de agregar capital simbólico a seu acervo e, por consequência, a seu trabalho como um todo. Interessante pensar que o título Memória do Mundo pode reverberar de maneira positiva, gerando efeitos benéficos após a nominação, seja em um poder aumentado de atrair recursos de financiamento junto a editais de fomento, seja na visibilidade que o selo da Unesco possui no contexto 
contemporâneo. Por outro lado, existem registros do MOW cujos desdobramentos geraram tensóes diplomáticas entre os países envolvidos, estendendo as disputas para além do certame responsável por indicar quais acervos detêm o título de patrimônio documental da humanidade.

No caso do presente artigo, nosso recorte destaca três candidaturas apresentadas ao Comitê Consultivo Internacional recentemente: "Vida e obra de Ernesto Che Guevara: dos manuscritos originais da adolescência e juventude aos diários de campanha da Bolívia”, proposição binacional conjunta de Bolívia e Cuba, de 2012; "Documentos do Massacre de Nanquim", formalizada pela China em 2014; e "A Guerra da Tríplice Aliança: representaçôes iconográficas e cartográficas", tendo Brasil e Uruguai como países proponentes, no ano de 2014. Além de analisar alguns argumentos que foram mobilizados na construção dos dossiês apresentados à Unesco, sublinharemos as consequências advindas do reconhecimento concedido a essas propostas enquanto Memória do Mundo Internacional. A pesquisa histórica foi realizada no acervo do MOW, localizado no Arquivo Nacional, instituição responsável por abrigar os documentos do programa no Brasil, e na sede da Unesco em Paris, detentora de registros importantes das candidaturas internacionais.

Inspirados pela metodologia da etnografia de arquivos (Cunha, 2005; Heymann, 2012), adotamos a perspectiva de adaptá-la a outro ponto de vista: a etnografia da política de arquivos. O objeto de investigação são os documentos produzidos no âmbito do Memória do Mundo, náo no interesse de contextualizar a constituição desses acervos, mas por um viés interpretativo que indaga como as concepçóes do MOW repercutem na seleção de proposições, além de quais decorrências a política de reconhecimento patrimonial traz para a gestão da memória (Heymann \& Arruti, 2012). Adotar a etnografia da política de arquivos como viés metodológico implicou uma série de procedimentos: acompanhar as práticas dos agentes e das instituiçóes que representam; apreender a rotina do programa; realizar entrevistas com sujeitos ${ }^{2}$; e negociar minha inserção nesse campo permeado de conflitos e disputas, em que a Unesco se sobressai como instituição dominante, por seu grande capital simbólico (Bourdieu, 1996).

\section{Sobre o MOW: breve histórico, critérios e valores}

A destruição da Biblioteca Nacional de Sarajevo, na atual Bósnia e Herzegovina, por ocasiáo da Guerra dos Bálcâs Europeu, em 1992, tornou-se uma espécie de catalisador para o surgimento do programa Memória do Mundo. Devido à perda de mais de dois milhóes de livros, incluindo títulos raros que abrangiam os períodos dos impérios Austro-Húngaro e Otomano, o então diretor-geral da organização, Federico Mayor, priorizou as tratativas que vinham sendo projetadas no setor de Comunicação e Informação da Unesco desde o final dos anos 1980. Já existia um Plano de Trabalho que propunha mapear coleçóes raras de documentos que estivessem em risco de desaparecer ou de sofrer perdas em função de calamidades naturais (enchentes, furacóes), desastres provocados pelo homem (guerras, incêndios) ou dificuldades estruturais das instituiçóes de guarda. Para tanto, a Unesco acionou e mobilizou uma rede de parceiros, entre os quais se destacaram o Conselho Internacional de Arquivos (ICA) e a Federação Internacional de Associaçóes e Instituiçóes Bibliotecárias (IFLA).

O fato de o Memorial do Mundo estar inserido no setor de Comunicação e Informação da Unesco não é mera casualidade. Desde o início do seu funcionamento, a agência atentava para os debates informacionais que tomavam forma no contexto mundial, em meados do século XX. Apesar do conhecimento produzido sobre arquivos e bibliotecas se concentrar nos países de economia mais desenvolvida, é possível perceber um movimento de circulação desse campo do conhecimento que começava a atingir outras nações. Se, por um lado, França, Estados Unidos, Holanda e Canadá foram pioneiros nos debates acerca da gestão de documentos, países como México e Brasil conseguiam avançar na qualificação de seus profissionais e instituiçóes a partir de intercâmbios, cursos de formação, traduções de obras de referência na área e desenvolvimento de projetos com parcerias internacionais. Atenta à configuração do campo dos arquivos e das bibliotecas entre os países, e consolidando seu papel de intermediadora, a Unesco 
procurou inserir, permanentemente, os debates sobre preservação, acesso e circulação informacionais na sua agenda programática. O MOW surge, portanto, relacionado à política de informação e comunicação, setores que se tornaram estratégicos e são mencionados como fatores de desenvolvimento nos países.

O instrumento propriamente dito da patrimonialização dos acervos documentais - denominado pela Unesco registro e/ou nominação - foi aplicado pela primeira vez somente em 1997. Os critérios e valores que norteiam os processos de patrimonialização pelo MOW já sofreram modificações ao longo dos mais de vinte anos de funcionamento do programa. Em um primeiro momento, com as Diretrizes para salvaguarda do patrimônio documental, de 1995, foram adotados sete critérios - influência; época; lugar; pessoas; assunto ou tema; forma e estilo; valor social -, alinhados às práticas de patrimonialização que já eram comuns na Unesco desde o final da década de 1970. Percebese que a atribuição de valor patrimonial levava em conta os sujeitos ou grupos históricos atuantes em determinado tempo e espaço, e que tivessem marcado e contribuído de forma significativa para a trajetória da humanidade. Ainda que as noçóes de cultura ou história mundial incorressem nos riscos do etnocentrismo, os documentos que poderiam receber a alcunha de memória do mundo deveriam ser produzidos pelo contexto social, cultural e até espiritual das culturas nacionais. Adotou-se, portanto, um procedimento similar ao que já era praticado na confecção da Lista do Patrimônio Mundial, com uma diferença: o foco se voltava aos esquecidos acervos documentais.

Quando o MOW completou uma década, em 2002, lançou-se uma nova versão das Diretrizes do programa. É perceptível a guinada para o viés arquivístico-documental, sendo o estabelecimento de critérios e valores a serem considerados fundamentais para a concessão do título de Memória do Mundo uma das formas de visualizar essa mudança. Ela pode ser notada, também, por exemplo, nas equipes responsáveis, anteriormente mais interdisciplinares e, nas efemérides dos dez anos do MOW, constituídas por membros da área da documentação. O programa estabeleceu uma hierarquização entre as categorias valorativas: o primeiro critério, em ordem de importância, foi a autenticidade, do ponto de vista da arquivologia, seguido pela ideia de "único e insubstituível”, também comum nas discussóes sobre arquivos. Apesar de cinco dos sete critérios iniciais terem sido mantidos - foram suprimidos os itens "influência" e "valor social" -, três novas noções sublinhavam a conservação física dos documentos: raridade, integridade e ameaça.

Por sua vez, o programa Memória do Mundo passou incólume às discussóes sobre a noção do autêntico fomentadas pela Unesco, em especial no setor de Cultura. Na inclusão do critério de autenticidade, a partir da publicação das Diretrizes do Patrimônio Documental de 2002, não havia qualquer referência aos debates que, a partir da década de 1980, flexibilizaram, em grande medida, a noção de autenticidade para bens culturais. Pelo contrário, as atençôes se voltaram exclusivamente para os acervos documentais, enquanto bem arquivístico que se distanciava de bens culturais materiais e intangíveis. Nesses termos, o MOW recorreu às referências conceituais do campo arquivístico para identificar documentos autênticos, ao mesmo tempo em que se utilizou da concepção "dura" de autenticidade comum no campo do patrimônio até os anos 1970 . Desse modo, o programa delimitou seu universo de atuação, em consonância com as iniciativas do setor de Comunicação e Informação.

A busca obstinada pela autenticidade documental marcou manuais de arquivologia, pouco afeitos a reflexôes que problematizassem essa noção. Identificar documentos autênticos tornava-se, assim, uma ação corriqueira, sobre a qual não cabiam questionamentos, bastando seguir as orientaçôes para identificar registros condizentes com os princípios intricados de criação, tratamento e guarda documental que assegurassem a autenticidade de determinado acervo documental. Uma das críticas a essa visão utilitarista veio do filósofo Jacques Derrida, que, segundo Luciana Heymann, trouxe reflexóes instigantes aos acervos documentais:

Em colóquio sobre a história da psiquiatria, realizado em Londres em 1994, Derrida expressou sua crítica à ideia de que os documentos armazenados nos arquivos preservam uma 'originalidade' e uma 'autenticidade' capazes de lhes conferir fidedignidade, da mesma forma que o subconsciente freudiano não constitui o repositório imaterial 
da memória individual. Implodindo com as dicotomias original/cópia, autêntico/artificial, dentro/fora, Derrida sustentou o argumento de que não há, nem jamais houve, um registro original, uma matriz 'interior' ou 'anterior' da verdade, coletiva ou individual, apenas traços que deixam traços. (Heymann, 2012, p. 25)

O espírito questionador de Derrida somava-se aos esforços que historiadores e antropólogos realizavam no intuito de repensar o arquivo enquanto problema social, político, epistêmico, e campo no qual se travam disputas de poder que buscam consagrar certas memórias e silenciar determinadas representaçóes do passado. Refletir sobre a autenticidade náo estava no escopo das competências assumidas pelo MOW.

\section{Consideraçôes a respeito da patrimonialização pelo MOW}

Como ponto de partida para nossa análise, constatamos que a seleção dos acervos ocorre a partir de um conjunto restrito de possibilidades; ou seja, os Comitês do Programa não têm a prerrogativa de escolher livremente os documentos para registro no Memória do Mundo. Existe um instrumento público de seleção, regulado a partir de um edital publicado regularmente, e que viabiliza a formalização de candidaturas oriundas de pessoas físicas e/ou jurídicas. O poder decisório dos membros especialistas é, portanto, exercido sobre um conjunto limitado de acervos documentais. A rigor, esse universo é formado pela conformação das candidaturas, em torno da qual se mobilizam instituiçóes e agentes que tomam contato com a publicidade do programa ou passam por seus treinamentos. No limite, podemos inferir que o rol de candidaturas se consolida diante de modos de operar a memória (Roque, 2013), uma vez que a proposiçáo de um acervo permite aos candidatos "esculpir" a forma do que se diz sobre a memória.

No caso do Memória do Mundo, o peso conferido ao ato de narrar torna-se ainda mais importante que o próprio bem, ou seja, a documentação produzida a partir do preenchimento dos campos do formulário adquire tamanha relevância que aparece como traço constituidor do programa. Apesar de ser uma forma de narrar, a fotografia perde espaço para a escrita nos processos de elaboração do dossiê do MOW:

Cada parecerista julga não no sentido da importância da documentaçáo, mas da instruçáo. A avaliação vai por aí. Não vai muito na importância, entre aspas, que a documentação tem por si, não. É da construçâo da candidatura, ou seja, nós avaliamos a candidatura, e não a documentação em si. (Peixoto, 2016)

Candidaturas amadurecem. É que nem uma tese: você faz um rascunho, depois faz outro, e outro. Você tem três, quatro meses para apresentar a candidatura; você não precisa apresentar aquele ano. Se você acha que ainda náo está boa, segura, continua trabalhando, apresenta no outro ano, porque o edital tem todo ano. (Scarpa, 2016)

Em ambas as falas, a atribuição de valor está atrelada à narrativa construída sobre o bem documental. Os dois entrevistados ocupam lugares de destaque no campo arquivístico brasileiro, mais precisamente no Arquivo Nacional (AN), instituição responsável por abrigar e adaptar o programa MOW no Brasil e, por consequência, manter vínculos de parceria com a Unesco. A estratégia de mobilizar argumentos convincentes sobre a relevância do acervo tem como objetivo obter uma representação que sensibilize os membros do Comitê, sendo por vezes necessário reescrever a candidatura.

As três candidaturas que analisaremos no presente artigo foram apreciadas, em diferentes momentos, pelo Conselho Consultivo Internacional do Memória do Mundo. O CCI é composto por quatorze membros considerados de notório saber em preservação documental, e se reúne a cada dois anos para deliberar os registros internacionais. A escolha dos nomes dos especialistas começa no interior do CCI: os próprios membros sugerem currículos a ser avaliados pela Secretaria Geral do programa. Posteriormente, os nomes dos possíveis novos membros passam por consulta junto às Comissóes Nacionais dos Estados-membros, para verificar se há alguma objeção ao ingresso do profissional no CCI. A nomeação precisa ser referendada pelo diretor-geral 
da Unesco e cada mandato é pessoal, com duração de quatro anos, podendo o membro ser reconduzido por igual período.

De maneira geral, o programa Memória do Mundo alinhou-se a outras açôes que já estavam em uso no interior da Unesco, ainda que não se observasse uma integração programática. A comparação com a Lista do Patrimônio Mundial Cultural e Natural é recorrente quando se fala sobre o MOW; a referência à Lista Representativa do Patrimônio Imaterial é menos comum. Contudo, é possível perceber que a listagem do Memória do Mundo fica subsumida em relaçáo às duas de maior repercussão. Ademais, notase que não existe uma integração programática entre as iniciativas da Unesco na lida com o patrimônio cultural. O MOW, gestado e mantido pelo setor de Comunicaçáo e Informaçấo, permanece mais isolado das açôes patrimoniais desenvolvidas no setor de Cultura, que reproduzem de maneira contínua a divisão artificial entre "patrimônio material" e "patrimônio imaterial".

A crítica à falta de compartilhamento de açóes em prol do patrimônio é objeto de análise de agentes externos à instituição:

A Unesco determinou que deve, como organização internacional, adotar políticas garantindo a abordagem interdisciplinar de todos os setores em todos os níveis, mas, na realidade, não iniciou totalmente os vínculos relevantes em todos os Programas. O Memória do Mundo teve algum sucesso limitado, por exemplo, com a sua campanha de arquivos escravos, mas não foi feita nenhuma tentativa de vinculá-lo ao projeto "Lugares de Memória, a Rota Escrava" dentro do Programa do Patrimônio Mundial. Do mesmo modo, sinergias óbvias com o Patrimônio Cultural Imaterial e o Programa Internacional para o Desenvolvimento das Comunicaçóes não foram abordadas e permanecem inexploradas. Todos eles têm o potencial de se apoiar mutuamente, complementar e não competitivo. ${ }^{3}$ (Unesco, 2008)

Isso evidencia a dificuldade de, mesmo no interior de uma mesma instituição, estabelecer diálogo entre áreas de conhecimento afins. A valorização do saber especializado pode significar a criação de fronteiras simbólicas que dificultam interconexóes de sentido e significado entre as representaçóes do patrimônio.

Ao analisar a lista do Patrimônio Imaterial, Marina Mafra argumenta que esta "corre o risco de tornar-se simplesmente um grande catálogo de maravilhas do mundo, ocasionando uma fixação pelo objeto patrimonial' (Garcia, 2014, p. 46). Tal prática já era costumeira na Unesco desde a Convenção do Patrimônio Mundial de 1972, e tornou-se um instrumento para nomear os bens culturais que tenham características "monumentais e excepcionais". O antropólogo Daniel Fabre aponta que as inscriçóes de bens, a partir da Convenção de 1972, reiteram e atualizam uma "carreira monumental" de monumentos e sítios que já gozavam de prestígio local (Fabre, 2010, p. 34). Ao se alinhar a essa prática deliberada de nominaçáo, entendemos que o MOW sofre ameaças semelhantes quando divulga os novos acervos que passam a integrar a lista do Patrimônio Documental. A saturaçáo da listagem de bens do Programa é uma tendência que tem se concretizado progressivamente: se nos primeiros cinco editais internacionais o número de registros foi de 120 , nas últimas cinco versóes a quantidade de nominaçóes subiu para 228, em sua grande maioria, acervos que já são reconhecidos como excepcionais e que, por aglutinar tal condição, reforçam seus respectivos capitais simbólicos em um contexto de constante rememoração.

Esse fenômeno, presente na sociedade ocidental contemporânea, é denominado "boom memorial" por Andreas Huyssen. Interessado na análise dos processos de rememoraçáo nos países ocidentais, o autor joga luz sobre a forte carga paradoxal que está presente em nosso cotidiano: "Quanto mais nos pedem para lembrar, no rastro da explosão da informação e da comercialização da memória, mais nos sentimos no perigo do esquecimento e mais forte é a necessidade de esquecer" (Huyssen, 2000, p. 20). A instabilidade do tempo e a fratura do espaço vivido contribuem para o agravamento do quadro em que estamos imersos.

Tal paradoxo - quanto mais lembrarmos, mais corremos o risco de esquecer - tem na representaçáo da amnésia a consequência direta do excesso da memória (Ricoeur, 2010). O que é agravado pela "nova estrutura de temporalidade, gerada pelo ritmo 
cada vez mais veloz da vida material, por um lado, e pela aceleração das imagens e das informaçóes da midia, por outro. A velocidade destrói o espaço, $e$ apaga a distância temporal' (Huyssen, 2000, p. 74). Segundo François Hartog, vivemos uma espécie de "presentismo dilatado" (Hartog, 2013) em que o passado parece se fundir ao presente, trazendo a todo momento nossa necessidade de rememorar, comemorar e patrimonializar, açóes que acontecem com grande frequência e em um ritmo cada vez mais acelerado. Hartog sublinha que, sintonizada com a memória, a noção de patrimônio tornou-se também saturada: "Assim como se anuncia ou se reclama memórias de tudo, assim tudo seria patrimônio ou suscetivel de tornar-se. A mesma inflação parece reinar" (Hartog, 2006, p. 268). A saturação patrimonial materializase na ideia de nomear e listar, temendo um tipo de futuro que se calca na "expectativa de um desastre"; ao recordar o antropólogo Daniel Fabre, David Berliner e Chiara Bortolotto destacam a expressão "o paradigma dos últimos" diante dessa visão um tanto apocalítica da história. Essa postura produz, entre outros resultados, a excessiva patrimonialização de bens culturais na contemporaneidade (Berliner $\&$ Bortolotto, 2013, p. 12).

Na publicação comemorativa dos vinte anos do MOW, a então diretora-geral da Unesco Irina Bokova encerra o prefácio com a seguinte afirmação:

Esse livro revela o patrimônio documental em toda sua diversidade. Ao longo de vinte anos, o programa Memória do Mundo ficou cada vez mais forte. Nós devemos ampliá-lo cada vez mais - aumentando as nominaçóes de todos os países e dando visibilidade à preservação de fontes de conhecimento excepcional. O Memória do Mundo atinge a maioridade em um momento em que preservar nosso patrimônio documental é mais importante do que nunca. (Unesco, 2012, p. 09)

O tom de entusiasmo assinala a intenção de expandir a política de patrimonialização de documentos para a totalidade dos Estados-membros da agência. O pressuposto de que o aumento de bens patrimonializados dará maior visibilidade a eles e, por consequência, à preservação dos acervos desconsidera os efeitos adversos do "boom memorial", como a possível saturação das listas do Patrimônio da Unesco e, no limite, o próprio esquecimento. Em contraste com as palavras otimistas da ex-diretora-geral, relatórios do MOW apontam para dificuldades operacionais do programa no setor de Comunicação e Informação; o baixo número de funcionários destacados para as atividades do MOW na sede da Unesco é um dos principais motivos apontados nos relatórios, além do reduzido investimento financeiro na promoção do programa como um todo.

\section{Diários de Che Guevara: novo capitulo dos conflitos norte-americanos na Unesco}

O título de Memória do Mundo concedido à documentação de Che Guevara em 2013 contribuiu para aumentar as tensóes entre o governo norteamericano e a Unesco. Nessa época, os EUA já haviam cortado sua subvenção anual à agência; a justificativa foi o ingresso da Palestina na organização em 2011 como Estado-membro, fato que fez da Unesco a única agência do sistema ONU a reconhecer a soberania dos palestinos. A 36 ${ }^{\mathrm{a}}$ Conferência Geral da Unesco, realizada entre os dias 26 de outubro e 10 de novembro de 2011, votou o ingresso dos palestinos na agência, com o seguinte resultado: 107 votos a favor, 14 contrários e 52 abstençóes. Com a aprovação da maioria do plenário, a Palestina tornou-se o $195^{\circ}$ Estado-membro da Unesco. Como retaliação à decisão coletiva, Estados Unidos e Israel anunciaram a suspensão das suas contribuiçóes financeiras à Organização (Coulais, 2015, p. 26-27).

Apesar de não contribuir financeiramente com a Unesco desde então, os Estados Unidos permaneciam vinculados à agência. A saída definitiva do país e de Israel ocorreu no início de 2018. Meses antes, o presidente norte-americano Donald Trump, e o primeiro-ministro de Israel, Benjamin Netanyahu, fizeram discursos contrários à entrada da Palestina na Unesco, explicitando o descontentamento com o título de patrimônio da humanidade concedido ao Centro Histórico de Hebron, na Cisjordânia, em 2017. Cabe frisar que, no caso dos diários patrimonializados de Che Guevara, o legado da figura mítica do biografado incomoda as autoridades 
norte-americanas. Por mais que os conteúdos desses documentos tragam informaçóes da época, mergulhada no contexto polarizado da Guerra Fria - o que já seria preocupante, por se contrapor às narrativas norte-americanas sobre o "perigo do comunismo" -, o título do MOW já aglutina um potencial simbólico de nomeação que se transfere do acervo documental para o próprio biografado. Nesses termos, é Ernesto Che Guevara que se tornou Memória do Mundo, tendo na memória escrita dos documentos sua forma de materialização.

O dossiê da proposição em torno de Che Guevara detalha da seguinte maneira o corpus documental:

1.007 documentos - agrupados num total de 8.197 páginas, de 1928 a 1967, relativos ao seu trabalho revolucionário, ensaios, artigos de jornal, materiais biográficos e obras pessoais, bem como a sua correspondência com diferentes pessoas e a sua família. (Unesco, 2013b)

Na sequência, há um detalhamento das condições em que os documentos foram produzidos e/ou acumulados:

431 são manuscritos de Che e 567 são sobre Che ou relacionados a ele [...]. É quase inteiramente constituída por documentos originais preservados pelo próprio Che. Muitos deles faziam parte de seus pertences enquanto viajava de um lado para o outro desde a década de 1950. (Unesco, 2013b)

A candidatura foi formalizada pelo Centro de Estudios Che Guevara, instituição localizada em Havana e criada a partir dos esforços da viúva de Che, Aleida March, em 1983, e pelo Banco Central de Bolivia, com sede em La Paz. A documentação sob guarda no país sul-americano recebeu uma menção interessante:

O diário boliviano, negociado e quase leiloado em Londres pela Sotheby's em 1986, foi recuperado pelo Ministério das Relaçóes Exteriores da Bolívia e mantido sob custódia nos arquivos do Banco Central da Bolívia. (Unesco, 2013b)
Realiza-se aqui uma espécie de biografia do documento, com destaque para o simbolismo do diário - nas palavras da proposição cubana-boliviana, "um documento único e insubstituivel que, além do mais, tem uma dimensáo especial na medida em que guarda um registro do último ano de vida de seu autor", (Unesco, 2013b) percebe-se a disputa pela posse do manuscrito. Os esforços diplomáticos para que o diário não fosse captado por colecionadores particulares são explicitados para valorizar a guarda atual. $\mathrm{O}$ próprio espaço onde está guardado, o arquivo de um banco - que remete a um cofre onde se protegem objetos valiosos - explicita a importância conferida ao diário de Che Guevara.

Contudo, o que mais pesa, em termos quantitativos e qualitativos, na proposta coletiva de Bolívia e Cuba é a referência à construção da figura política de Ernesto Che Guevara. Em diferentes trechos do formulário do MOW é possível verificar como essa questão se torna um dos principais motes da estratégia de convencimento da candidatura junto ao CCI do Memória do Mundo. A título de exemplificação, seguem algumas passagens:

Um exemplo do intelectual orgânico, o revolucionário que não conhece fronteiras; injetou na teoria marxista elementos criativos, antidogmáticos e humanistas através de uma sistematização conceitual que estava à frente de seu tempo; e ele foi capaz de compreender desde a juventude seu ambiente social, ultrapassando os horizontes limitados dos nacionalismos locais na América Latina e se tornando um revolucionário em escala continental e universal. (Unesco, 2013)

O autor uruguaio Eduardo Galeno é referenciado a partir de uma provocaçáo que lançara antes da formalização da proposta junto ao MOW: "Por que Che tem o hábito perigoso de continuar a nascer de novo"?, como resposta, o formulário da proposição binacional argumenta que "ele não era apenas um dos homens mais heroicos, mas também um dos mais talentosos, originais e humanos da sua geração"(Unesco, 2013b). Em seus trabalhos profundos e marcadamente profissionais, o escritor praticava o que pregava, anotava suas experiências, analisava-as para chegar 
a conclusōes práticas e as transformava em realidade concreta" (Unesco, 2013b).

O legado de Guevara é mobilizado como trunfo decisivo para a patrimonializaçáo do acervo, apresentado como atestado da atitude política de Che no mundo, tendo nas anotaçóes dos diários a materialidade de seus planos, realizaçóes e utopias. A possibilidade de apropriação do conteúdo desses documentos revela-se, também, como uma das grandes riquezas simbólicas do bem patrimonializado - um acervo documental dotado de traços históricos, políticos, culturais e ideológicos de uma das personalidades mais emblemáticas de um mundo marcado pelas disputas da Guerra Fria. Ademais, características dos documentos apresentados e traços do biografado parecem fundir-se; ambos são importantes no processo de fortalecimento da imagem de Guevara. Por outro lado, há de se ressalvar que parte da narrativa da candidatura vem acompanhada de uma supervalorização do biografado, como se este fosse dotado de atributos sobre-humanos. A expressão "à frente de seu tempo" corrobora esse tipo de construçáo, que pode deslocar o sujeito de seu contexto social e histórico.

Assim que a proposiçấo "Vida e obra de Ernesto Che Guevara" foi aprovada pelo CCI do Memória do Mundo, nos idos de 2013, setores da imprensa norteamericana manifestaram-se de forma marcadamente contrária à titulaçấo concedida pela Unesco; editoriais de alguns veículos de comunicação bradaram expressōes como "repreensível", "revoltante" e "injustificável". Destacamos dois títulos de editoriais de órgãos da imprensa norte-americanos: "Repreensivel: Unesco acrescenta obras de Che Guevara a patrimônio mundial' (Chasmar, 2013) e "A decisão da Unesco de homenagear Che Guevara prova que não merece o apoio dos Estados Unidos da América" (Schaefer, 2013). Os motivos que levaram o Conselho Consultivo Internacional a selecionar os diários de Che Guevara como um dos patrimônios documentais da humanidade não puderam ser averiguados na nossa pesquisa. A Unesco adota uma política contraditória de acesso aos documentos, no contexto contemporâneo. Disponibiliza um robusto repositório digital com fontes históricas importantes da trajetória institucional, mas, por outro lado, não permitiu acesso aos pareceres dos especialistas responsáveis pela avaliação das propostas apresentadas a cada edital; nem mesmo minha pesquisa in loco, na sede da Organização, em Paris, na França, possibilitou a imersão nesses documentos.

Apesar dessa condição de inacessibilidade às fontes de pesquisa, é possível problematizar aspectos relevantes das circunstâncias da proposição. A iniciativa veio de dois países que se posicionam como oponentes aos Estados Unidos no plano internacional: Cuba, desde a Revoluçâo de 1959, e a Bolívia, onde o governo do presidente Evo Morales mantinha um discurso nacionalista e antiamericano. A proposição apresentase, sob o ponto de vista dos norte-americanos, como um enfrentamento de seu poder de gestar a memória em torno da imagem de Che Guevara. Se para o governo dos EUA a figura do revolucionário é vista como uma ameaça à ordem democrática, para muitas outras naçóes Che é um dos líderes do movimento considerado pelos cubanos como libertário e que posteriormente alinhou Cuba ao bloco socialista. Assim, com a proposta, despontaram perturbaçōes diplomáticas na Unesco, protagonizadas por representantes dos Estados Unidos. A crise, iniciada no programa, logo se estendeu para outros espaços de decisão da organização - como as reunióes da Conferência Geral e do Comitê Executivo -, gerando sensibilidades e um processo de desgaste do MOW. O programa passou a ser bastante questionado pelos Estados Unidos, que sugeriam, inclusive, sua extinção (Gerard, 2017). O entrevistado, que ocupa um cargo de destaque no setor de Comunicação e Informação da Unesco, afirmou que as duas maiores instâncias de decisão da Unesco - Conferência Geral e Conselho Executivo - sofreram efeitos desses embates. O Memória do Mundo, que até então não tinha tanta visibilidade como o Programa do Patrimônio Mundial, passou a estar na pauta dos Estados-membros que participavam dessa iniciativa da Unesco.

\section{Prolongamento da guerra entre China e Japão}

A ameaça de corte da contribuição orçamentária do governo japonês à Unesco pairou durante todo ano de 2016. A imprensa internacional noticiava o impasse instalado no interior da agência desde que a candidatura "Documentos do Massacre de Nanquim", apresentada pela China, recebeu o título de patrimônio 
documental da humanidade. Entre outros, foram publicados artigos como "Japão retém verba à Unesco após polêmica sobre massacre de Nanquim" (O Globo, 2016); "Japão ameaça barrar fundos para Unesco por atrito com China sobre massacre de Nanquim" (Takenaka, 2015); "Japão suspende financiamento da Unesco após repercussäo do massacre de Nanquim" (The Guardian, 2016). Somente no momento derradeiro de fechamento das contas anuais o Japão realizou a transferência dos recursos previstos para a Unesco. "Às vésperas das festas do Natal de 2016, tivemos um respiro financeiro, quando finalmente recebemos a contribuição japonesa, que representa cerca de 5\% do nosso orçamento", revelou um dos funcionários do setor de Comunicação e Informaçấo da Unesco (Gerard, 2017).

O programa Memória do Mundo reacendeu a disputa entre Japão e China pela gestáo da memória dos acontecimentos vividos pelos dois países na Segunda Guerra Mundial. Ao apresentar a proposta, montada a partir da reuniáo de acervos localizados em sete instituiçôes - Central Archives of China; The Second Historical Archives of China; Liaoning Provincial Archives; Jilin Provincial Archives; Shanghai Municipal Archives; Nanjing Municipal Archives; $e$ The Memorial Hall of the Victims in Nanjing Massacre by Japanese Invaders -, a China afirmava que os documentos selecionados "têm autoridade indiscutível e autenticidade, sendo o testemunho do massacre de Nanquim, um fato histórico" (Unesco, 2015). Em diversas passagens da candidatura formalizada pelos chineses percebe-se o tom de denúncia e a clara intenção de condenar os japoneses pelos crimes cometidos. A narrativa descreve uma série de detalhes que procuram atestar a violência contra civis, em especial mulheres, outorgando ao título almejado de "memória do mundo" o poder simbólico de lembrar e testemunhar algo quase sempre esquecido no âmbito internacional, e de reparar a dor coletiva dos chineses. De acordo com a candidatura, 20 mil mulheres chinesas foram raptadas, violentadas ou mortas pelos japoneses durante a invasão da antiga capital, Nanquim.

Jogar luz sobre esse crime hediondo contra a humanidade, tendo como respaldo uma documentação internacionalmente reconhecida, alinha-se à perspectiva de "dever de memória" (Nora, 1993) como um caminho legítimo para reconhecer abusos sofridos e reparar o sofrimento causado por um conflito bélico traumatizante. Por sua vez, estudos revisionistas japoneses minimizam a ocorrência dessa matança. A via do esquecimento, ademais, mostra-se como caminho usual nesse tipo de evento em que determinada parte se vê constrangida a assumir um crime humanitário.

A reaçáo japonesa foi imediata. $\mathrm{O}$ trabalho da Delegação Permanente do Japão no cotidiano da Unesco mostrou-se intenso depois que a candidatura chinesa foi protocolada na Secretaria do MOW, localizada em Paris. Segundo um dos funcionários da organização, "os japoneses ficaram revoltados com a candidatura. Afirmavam que a versäo dos chineses sobre o conflito não tinha credibilidade e que ofendia o povo japonês" (Gerard, 2017). A ata da reuniáo do Comitê Consultivo Internacional do programa Memória do Mundo que aprovou os "Documentos do Massacre de Nanquim" em 2015, além de outras 48 proposiçóes oriundas de diferentes países, revela parte das tensōes vivenciadas na instituição:

Durante o processo de avaliação, houve uma forte pressão exercida sobre a diretora-geral da Unesco, sobre a equipe da Unesco e sobre os membros do Subcomitê de Registro do MOW a favor e contra algumas das candidaturas apresentadas. [...] Na reunião anterior, o Subcomitê de Registro expressou sua preocupação com a crescente pressão e observou que isso poderia prejudicar a integridade do Programa MOW. (Unesco, 2015b)

O trecho transcrito é a única passagem elucidativa, ainda que não faça referência direta, sobre a controversa gerada pela candidatura chinesa. Na maioria das vezes, a Unesco evita detalhar informaçóes sobre as reuniōes do MOW. Em vez do conteúdo dos debates entre os membros do CCI sobre as proposiçóes apresentadas, e da contagem de votos do plenário que decide quais acervos documentais receberáo o título, temos apenas a informação imprecisa de que "houve uma forte pressão", denotando que a disputa pela memória não se faz sem conflito ou impasses. Por outro lado, a lista de presença dessa reuniáo revela um detalhe significativo: dos doze encontros internacionais do 
programa realizados até ali, esse foi o que teve o maior número de presentes, inclusive autoridades japonesas e chinesas, na condição de "observadores".

Apesar da manutenção do título do MOW por parte da Unesco, o Japáo recuou da ameaça e manteve a transferência de recursos para a agência. Foi preciso um trabalho de bastidores entre a Unesco e os representantes do Estado japonês para atenuar os efeitos do registro do Memória do Mundo. Durante meu trabalho de pesquisa na sede da Unesco, entre 2016 e 2017, percebi que o impasse era assunto evitado pelos funcionários. Nas entrevistas que realizei, e na minha observação como participante, ficou nítido o esforço para esquecer a polêmica e silenciar uma memória tão beligerante. As discussóes no âmbito do programa ficaram muito na tentativa de despolitizar o MOW, como se fosse possível separar a dimensão política da memória de alguns acervos patrimonializados. Aliás, o próprio ato de patrimonializar já é uma ação política, com desdobramentos e usos que oscilarão conforme as circunstâncias históricas, em meio às hibridações do passado, presente e futuro.

\section{Narrativas de uma guerra silenciada}

A terceira e última candidatura chancelada pelo Memória do Mundo com potencial conflitivo considerável - ainda que não tenha chegado a render polêmicas - foi a "A Guerra da Tríplice Aliança: representações iconográficas e cartográficas". Sua primeira versão ocorreu no edital brasileiro de 2009, quando o Arquivo Histórico do Exército formalizou a proposição "Fundo Guerra do Paraguai". Os documentos são em sua totalidade manuscritos, reunidos a partir das atividades do Ministério da Guerra entre 1864 a 1870, que "tratam desde a administração militar, movimentação das tropas, requisiçôes de materiais, até o transporte de prisioneiros paraguaios para o Brasil' (Unesco, 2009). A organizaçáo dessa documentação, apresentada como "Memória do Mundo do Brasil", segue a perspectiva oficial das Forças Armadas acerca do conflito, na qual se destacam "informaçóes sobre recrutamento, armamento, treinamento, transporte e cuidados médicos" pelo olhar dos "comandantes e oficiais", assim como dos "combatentes anônimos". A justificativa sobre a autenticidade do acervo é assim exposta: "É uma documentação autêntica composta por Ordens do Dia (impressas) relativas aos diversos comandos durante a Campanha e correspondência entre as autoridades aliadas (brasileiras, argentinas e uruguaias) em códices manuscritos" (Unesco, 2009).

Já a proposição aprovada no Comitê Regional (Mowlac) em 2013 traz mudanças significativas. Oito instituiçóes se somam aos proponentes: Arquivo Histórico e Mapoteca Histórica do Itamaraty, Arquivo Nacional, Diretoria do Patrimônio Histórico e Documentaçáo da Marinha, Fundação Biblioteca Nacional, Museu Histórico Nacional, Museu Imperial, Museu Nacional de Belas Artes e Instituto Histórico e Geográfico Brasileiro. A candidatura passava a contar com o apoio do Ministério das Relaçóes Exteriores, e o nome fora alterado para "A Guerra da Tríplice Aliança: representações iconográfica e cartográfica”, o que se manteve na apresentação ao MOW Internacional, no ano seguinte. Vemos que a alcunha "Guerra do Paraguai" é substituída pela expressão "Tríplice Aliança”, transmitindo a ideia de união de forças em prol de um objetivo comum. Além disso, o destaque passava a ser conferido aos tipos de gênero documental - iconográfico e cartográfico -, em contraposiçáa ao termo generalista utilizado pelo Arquivo Histórico do Exército na candidatura nacional, "fundo":

A candidatura da Guerra do Paraguai foi muito interessante porque nós formamos uma equipe muito unida, muito coesa. Liderada pelo Museu Imperial, mas tínhamos colegas do Arquivo do Exército, do Museu da Marinha, do Itamaraty. [...] O que nós pensamos desde o início era em escolher um tema ou uma temática que contemplasse a diversidade dos conjuntos e, ao mesmo tempo, fosse robusta, no sentido de dar conta dessa questáo tấo polêmica, táo delicada. E escolhemos a documentação iconográfica. Nós inserimos cartografia e imagens, enfim, desenhos ou mesmo pinturas sobre papel, produzidas no período da Guerra até o século XX. E uma vez definido o escopo [...], passamos a atuar efetivamente no âmbito da comissão de redação, de forma muito diretiva. Foi interessante contar com os militares porque, nesse sentido, eles são 
muito rigorosos em termos de disciplina. $\mathrm{Na}$ elaboração desse dossiê não houve nenhuma discussão, nenhum questionamento, conflito. Muito pelo contrário. A atuação da comissão foi muito plena, harmoniosa”. (Peixoto, 2016)

A participação de agentes de instituições museológicas, arquivísticas e militares na construção do argumento da candidatura transcorreu sem conflitos ou questionamentos. Essa parece ser a condição necessária para a gestão da memória: a coesão do trabalho de reuniáo e ordenamento do acervo, que deverá se refletir, também, na coerência e na harmonia de visões desejadas para a conformação da memória. Evitam-se abordagens que possam suscitar polêmica sobre um tema amplamente debatido na historiografia. Gostaríamos de inferir que o acervo apresentado como documento-monumento (Le Goff, 1996) opera, do mesmo modo, a monumentalização do evento histórico, desconsiderando a prática historiográfica crítica, que se faz no intercâmbio e no confronto de leituras.

Ao apresentar "A Guerra da Tríplice Aliança que emerge das fontes fotográficas", a candidatura descreve o acervo da seguinte forma:

A história política e militar da Guerra da Tríplice Aliança é facilmente compreendida por causa da enorme historiografia sobre o evento; textos produzidos a partir de documentos escritos, de documentos oficiais escritos. No entanto, a compreensão do conflito poderia ser interpretada, ou mesmo alterada, com o surgimento de novas fontes. Os comandantes militares agora apareciam cercados por soldados recrutados e voluntários da pátria, muitos deles índios, mulatos e negros. Morte e pobreza aparecem no fotojornalismo sobre os campos de batalha: uniformes rasgados, prisioneiros paraguaios, populaçóes locais famintas e as ruínas das fortificaçóes paraguaias. Mas a religiosidade popular também estava presente, no registro de procissóes religiosas nos campos brasileiros. Imagens dos acampamentos mostram a interação entre os comandantes e aqueles sob seu comando, e sua diversidade étnica. (Unesco, 2014)
A descrição dos documentos fotográficos, litográficos, iconográficos e cartográficos procura evidenciar o ponto de vista ou a participação de mulheres, crianças e soldados negros, assim como a convivência diária entre comandantes militares e soldados nos acampamentos e fortificaçóes da guerra. A candidatura associa, portanto, o ineditismo da proposta, supondo que tais documentos do conflito sejam pouco estudados, à possibilidade de uma apreensão sociocultural da guerra, indicando esses aspectos para construir a significância mundial do acervo. Oferece-se, apesar da resistência do discurso dos agentes proponentes, uma versão sobre a guerra:

De um lado, [ela] levou à completa destruição da organização econômica paraguaia e a um fraco posicionamento no cenário geopolítico regional. Por outro lado, a vitória, paradoxalmente, não trouxe prosperidade aos demais países. [...] É sobretudo nesse sentido que não há vencedores nem vencidos. (Unesco, 2014)

Para um dos entrevistados, a proposição não configura um problema diplomático com o Paraguai: "A gente optou por não fazer um viés triunfal. O viés era basicamente a questão da iconografia, da cartografia, a questão da etnografia da região" (Barroso, 2016). A potencialidade das imagens enquanto fonte de pesquisa é, contudo, subestimada diante da evocação de seu papel para silenciar e neutralizar o conflito.

Nominada pelo MOW Internacional em 2015, a candidatura "A Guerra da Tríplice Aliança: representaçōes iconográficas e cartográficas" foi uma proposição coletiva de Brasil e Uruguai. Os editais do Memória do Mundo permitem que "dois ou mais países" apresentem "propostas conjuntas relativas a coleções divididas entre diferentes proprietários ou custódios. Esse tipo de colaboração é fortemente encorajado" (Unesco, 2002, p. 26). Se as candidaturas podem abranger mais de dois países, por que a Argentina ficou de fora do conjunto de instituiçóes proponentes, com oito brasileiras e uma uruguaia? E uma pergunta ainda mais constrangedora se impóe: como sustentar uma candidatura que toca em questôes sensíveis e traumáticas sem envolver o povo paraguaio? 
Quando indagados sobre as tratativas de inclui os paraguaios, os agentes do Comitê MOW Brasil dizem:

Não foi um ponto polêmico o Paraguai ter ficado de fora porque a documentação que o país possui sobre a Guerra do Paraguai foi copiada do acervo do Arquivo Nacional. Uma realidade do final da guerra é que o Paraguai não ficou com a documentação. $\mathrm{O}$ país foi arrasado. $\mathrm{O}$ Ministério das Relações Exteriores nos pediu essa colaboração, digitalizamos e mandamos tudo que tínhamos sobre o Paraguai para lá. [...] Foi escolhida propositalmente a documentação iconográfica para evitar a interpretação ideológica da Guerra do Paraguai, já que com a imagem não tem como negar o que está acontecendo. Foi feita uma consulta ao Paraguai, ao Comitê Paraguaio, se ele teria algum óbice a essa candidatura, porque o que a gente não queria era uma polêmica, ofender o Paraguai, e que o Paraguai chegasse ao Comitê Internacional para fazer um protesto, como houve em outros casos. E o governo paraguaio, muito civilizadamente, disse: "Não temos nenhum óbice à candidatura. É história, apoiamos sua preservação". (Scarpa, 2016)

Um dos colaboradores da candidatura relata que houve consultas a instituiçóes argentinas, paraguaias e uruguaias. A Argentina alegou dificuldades operacionais e, por isso, segundo ele, náo se habilitou; já o Paraguai decidiu participar somente às vésperas da submissão, momento em que isso já era inviável (Scarpa, 2016).

Sobre os documentos autênticos para compor a candidatura, supōe-se que o único registro da memória da guerra que o Paraguai possui são as cópias enviadas pelo Arquivo Nacional brasileiro ao país. O que está em jogo, aqui, é a posição de poder que as instituiçōes de guarda oficiais ocupam na identificação de acervos legítimos que poderão ser valorizados pelo MOW, desconsiderando outros documentos, não oficiais, que inclusive, dado o recorte temporal adotado na candidatura - de 1857 a 1908 -, tenham sido produzidos depois da guerra, e possam fazer referência a sua memória. Entre os fundos reconhecidos como Memória do Mundo, estáo incluídos estudos e desenhos de artistas que se ancoram em narrativas dos vencedores, como esboços de pinturas históricas de Vitor Meireles, Pedro Américo, Eduardo De Martino e Diógenes Héquet, conhecidos por representar o triunfo da monarquia, e das imagens fotográficas de Luiz Terragno, Marc Ferrez, Carlos César, Zugarramurdi, Manuel Seron, Juan Carlos Hallemand e Javier López. Podemos supor que a inclusão de outras perspectivas documentais, que abarcassem a percepçáo e a memória de como os paraguaios vivenciaram a guerra, poderia se coadunar à perspectiva de valorização do diálogo e da paz, missão preconizada pela Unesco.

"É uma boa postulaçấo, com impacto na América do Sul; trata-se da reunião de nove instituiçóes: um conjunto documental importante, de valor pertinente. Recomenda-se postular ao registro internacional. Aprova-se a inscrição" (Unesco, 2013a). A ata da reunião do Mowlac que inscreveu o acervo sobre a Guerra da Tríplice Aliança como Memória do Mundo náo trata dos debates que podem ter ocorrido entre os membros do Comitê Regional. Menciona-se a presença de um paraguaio, qualificado como "ativista em direitos humanos" e um dos novos integrantes do Mowlac que tomavam posse, em referência a conversas realizadas com a diretora do Archivo Nacional do Paraguay, no intuito de incentivar proposições ao programa. Não havia representante argentino presente; um uruguaio e três brasileiros participaram do encontro.

\section{Memória do Mundo nutre conflitos diplomáticos}

Nosso olhar analítico sublinha que os processos de patrimonialização de acervos documentais, a partir do MOW, atenta-se para as circunstâncias sociais, políticas, culturais e históricas que integram as práticas simbólicas envolvendo diferentes sujeitos e instituiçóes. Em diferentes momentos de nossa inserção no campo da pesquisa a dimensáo política da patrimonialização dos acervos documentais é ressaltada pelos agentes, para os quais o Memória do Mundo seria um programa essencialmente técnico. Em razão dessa expertise, o MOW conseguiria desvencilhar-se, em sua trajetória de atuação, de atitudes políticas - 
tanto daqueles que apresentam proposiçóes quanto dos que julgam as candidaturas.

Muitos sujeitos que integram ou já participaram do MOW compartilham de duas concepçôes: os documentos são apolíticos; e a importância documental deriva de critérios técnicos. No que tange à trajetória da noção de patrimônio cultural, apenas recentemente a dimensão social e política dos bens passou a ser de fato considerada. Antes dessa mudança de paradigma, bastava um olhar acurado para desbastar o que sempre esteve ali: os valores históricos e artísticos nacionais intrínsecos. No caso do Brasil, os anos 1980 foram decisivos para o surgimento de novas problematizaçóes referentes à preservação do patrimônio cultural. No artigo em que realiza um mapeamento da história da noção de patrimônio no país, Márcia Chuva assinala duas ideias que apontam para uma perspectiva mais integradora do patrimônio cultural: os valores patrimoniais são suscetíveis aos diferentes contextos históricos; e "os sujeitos produtores de sentidos são vários, diferenciados e deveriam ser confrontados em fóruns de discussão" (Chuva, 2012, p. 163).

Entendemos que o patrimônio documental corre os mesmos riscos que ameaçam o patrimônio arquitetônico quando se desconsideram as dimensões sócio-históricas e políticas de sua constituição. Aqui é importante pontuar que este trabalho pressupóes tais dimensóes como sendo constitutivas do documento (Le Goff, 1996). Nessa medida, diferentemente do que querem os propositores da candidatura do Massacre de Nanquim, os documentos não podem revelar, por si mesmos, uma verdade única, como se os registros falassem por si, como defendia a visão positivista da história do século XIX. Concepçóes diferentes sobre o documento coexistem nas diversas áreas do conhecimento. Este artigo pretende contribuir, no entanto, com a discussão historiográfica acerca do novo estatuto adquirido pelo documento quando ele é objeto de patrimonialização, destacando os processos por meio dos quais acervos documentais se tornam Memória do Mundo.

Os registros iconográficos e cartográficos são representações datadas, carregadas de intencionalidade e parcialidade; diferentemente do que almejavam os proponentes das três candidaturas que destacamos, o manejo dessas fontes abre novas frentes de interpretação. Podemos pensar que é um contrassenso que um programa da Unesco, durante processos de patrimonialização de acervos que acionam memórias de guerras, se furte de promover o diálogo com os países envolvidos, confrontando as diferentes narrativas geradas no conflito ou ulteriores. Investir em silenciar as oposiçóes ou polêmicas suscitadas pelos documentos equivale a trazer para o primeiro plano os embates e mal-entendidos sobre a gestão da memória, como aqueles que voltaram a se acender, entre China e Japão, com os "Documentos do Massacre de Nanquim".

Nosso foco foi jogar luz sobre a "ponte" semântica estabelecida pelo "patrimônio documental", com consequências tanto para o debate historiográfico quanto para a instrumentalização política em curso nos organismos internacionais, com disputas e reapropriações da gestão da memória. Embora o campo arquivístico se aproprie de conceitos do campo do patrimônio cultural, facilitando a construção de terminologias como "patrimônio documental", este último se torna praticamente incomensurável quando é traduzido apenas pelas características físicas daquilo que se vê, sem que se evidenciem as intencionalidades e os agenciamentos do documento que se torna patrimônio. O documento não fala per si, mas a partir das leituras e apropriaçóes que, ademais, não se mantêm as mesmas ao longo do tempo; antes, sofrem alteraçôes e adaptaçôes de sentido, a partir de novos atores e acontecimentos que se dispõem em cena.

Em reflexóes recentes acerca do interesse coletivo pela noção de patrimônio, Daniel Fabre concebeu o conceito de "emoção patrimonial" (Fabre, 2013). Esta categoria permeia diferentes indivíduos e grupos sociais, adquirindo características conforme as nuances do processo de patrimonialização. Muitas vezes o ato de patrimonializar ocorre sem emoção, em especial quando é fomentado por instituições especializadas e se restringe ao círculo dos "técnicos do patrimônio". Ainda muito restrito ao campo dos especialistas, o MOW perde a oportunidade de ampliar o diálogo coletivo quando ocorrem situações polêmicas, como no caso das três candidaturas apresentadas nesse artigo. Em lugar de ampliar os canais de interlocução para além dos espaços formais de representatividade dos 
Estados-membros - o que poderia ser desdobrado em discussóes historiográficas com outras iniciativas da própria Unesco, como sua conhecida área da Educação, por exemplo -, os coordenadores do Memória do Mundo optam pela via do silenciamento, como se essa postura fosse suficiente para camuflar os embates e conflitos suscitados pelas memórias e visões da história.

A orquestração da política do MOW revela que a Unesco é constrangida pelo desafio de administrar um campo de atuação para o patrimônio documental, muitas vezes visto como algo de pouca visibilidade e recursos escassos. Contudo, a depender de algumas candidaturas e seus respectivos processos de patrimonialização, o processo de constituição dos acervos como patrimônio fica sujeito às idiossincrasias das ações hegemônicas e contra-hegemônicas dos sujeitos e Estados envolvidos. O Memória do Mundo, muitas vezes invisível dentro da própria Unesco, torna-se uma iniciativa permeada por um complexo potencial de conflitos diplomáticos que, caso continuem revisitando o passado a partir de embates de memórias, estenderá as disputas para contextos diversos e, até então, não considerados. Tratase, em grande medida, de reforçar uma característica presente na Unesco desde a sua fundação: a tentativa utópica de buscar um caminho conciliatório em um cenário no qual disputas, no presente, pelo passado tensionam as perspectivas para o futuro entre os Estados-membros.

\section{Notas}

1 Sigla em inglês para Memory of the World, MOW é marca identitária do programa e será utilizada no presente artigo para identificar essa iniciativa da Unesco.

2 Apesar de meus entrevistados terem concordado com a gravação e a transcrição das conversas, e até mesmo autorizado o uso acadêmico de suas falas, minha opção foi utilizar nomes fictícios. Por serem agentes produtores de memórias, atuantes no campo dos arquivos, permeado de disputas, avaliei que a divulgaçáo dos nomes poderia trazer mais problemas e tensóes do que resultados benéficos para a pesquisa como um todo.

3 Tradução de minha autoria, como as demais, do espanhol, do francês e do inglês, incluídas nesse artigo.

\section{REFERÊNCIAS BIBLIOGRÁFICAS}

BAMOUNI, Babou Paulin (1981), "L'Unesco et l'information: aspect historique et organization». Dissertação (Mestrado de Estudos Aprofundados em Ciências da Informação e da Comunicação). Universidade de Direito, de Economia e de Ciências Sociais de Paris II, Paris.

BARROSO, Julio. (2016). Entrevista realizada no Rio de Janeiro, 05/04/2016, RJ, Brasil.

BERLINER, David \& BORTOLOTTO, Chiara. (2013), "Introduction. Le monde selon l'Unesco". Gradhiva, n. 18, pp. 4-21.

BOURDIEU, Pierre. (1996), Razóes práticas: sobre a teoria da ação. Campinas: Papirus.

Chasmar, Jessica. (2013), “'Reprehensible': Unesco adds Works of Che Guevara to World Register". The Washington Times, 23 jul (Home/News/ World). Disponível em <www.washingtontimes. $\mathrm{com} /$ news $/ 2013 /$ jul $/ 23 /$ reprehensible-unescoadds-works-che-guevara-world-/>, consultado em 18/09/2019.

CHUVA, Márcia. (2012), "Por uma história da noção de patrimônio cultural no Brasil”. Revista do Patrimônio Histórico e Artístico Nacional, n. 34, pp. 147-165.

COULAIS, Alizé. (2015), «L'Unesco: une image de marque? Analyse de la comunication externe de l'Unesco». Dissertação (Mestrado em Ciência Política com ênfase em Relações Internacionais). Instituto de Estudos Políticos de Paris, Escola de Doutorado de Ciência Política, Paris.

CUNHA, Olívia. (2005), "Do ponto de vista de quem? Diálogos, olhares e etnografias dos/nos arquivos". Estudos Históricos, n. 36, pp. 3-5.

FABRE, Daniel. (2010), «Introduction. Habiter les monuments». In: FABRE, Daniel e IUSO, Anna (orgs.). Les monuments sont habités. Paris: Editions de la Maison des Sciences de l'Homme.

FABRE, Daniel. (2013), Émotions patrimoniales. Paris: Maison Des Sciences de L'homme.

GARCIA, Marina. (2014), "Fabricando patrimônios: a Unesco como arena de reconhecimento". E-cadernos CES [online], 21, pp. 32-51. https:// journals.openedition.org/eces/ 1748

GERARD, Louis. (2017). Entrevista realizada em Paris, 10/02/2017, França. 
HARTOG, François. (2006), "Tempo e Patrimônio". Varia Historia, v. 22, n. 36, pp. 261-273.

HARTOG, François. (2013), Regimes de historicidade: presentismo e experiencias do tempo. Belo Horizonte: Autêntica.

HEYMANN, Luciana \& ARRUTI, José Maurício. (2012), "Memória e reconhecimento: notas sobre as disputas contemporâneas pela gestão da memória na França e no Brasil”. In: GONÇALVES, Márcia de Almeida (org.). (2012), Qual o valor da história hoje? Rio de Janeiro: FGV, pp. 96-119.

HEYMANN, Luciana. (2012), O lugar do arquivo: a construçáo do legado de Darcy Ribeiro. Rio de Janeiro: Contracapa/Faperj.

HUYSSEN, Andreas. (2000), Seduzidos pela memória: arquitetura, monumentos, midia. Rio de Janeiro: Aeroplano.

LE GOFF, Jacques. (1996), História e memória. Campinas: Unicamp.

MACEDO CASTRO, João Paulo. (2005), “Unesco: Educando os jovens cidadãos e capturando redes de interesses: uma pedagogia da democracia no Brasil". (2005), tese de doutorado em Antropologia Social. Universidade Federal do Rio de Janeiro.

MAUREL, Chloé. (2005), «L'Unesco de 1945 à 1974». Tese de doutorado em História Contemporânea. Université de Paris I (Panthéon-Sorbonne), Paris.

NORA, Pierre. (1993), "Entre memória e história. A problemática dos lugares". Projeto História, n. 10, pp. 7-28.

O Globo. (2016). “Japão retém verba à Unesco após polêmica sobre massacre de Nanquim”. O Globo, 14 out. (Sociedade). Disponível em <www.oglobo. globo.com/sociedade/japao-retem-verba-unescoapos-polemica-sobre-massacre-de-nanquim->, consultado em 18/09/2019.

PEIXOTO, Paulo. (2016). Entrevista realizada no Rio de Janeiro, 22/03/2016, RJ, Brasil.

RICOEUR, Paul. (2010), A memória, a história e o esquecimento. Campinas: Unicamp.

ROQUE, Ricardo. (2013), "A circulação de histórias e coleçóes nos impérios coloniais. Poderes, saberes, instituiçôes”. In: JERONIMO, Miguel Bandeira (org.). O Império Colonial em questão (sécs. XIXXX). Lisboa: Ediçóes 70, pp. 455-485.

SCARPA, Sonia. (2016). Entrevista realizada no Rio de Janeiro, 28/03/2016, RJ, Brasil.
Schaefer, Brett. (2013), "Unesco decision to honor Che Guevara proves it doesn't desserve US support”. Fox News, 12 ago. (Opinion). Disponível em < www.foxnews.com/opinion/unesco-decision-tohonor-che-guevara-proves-it-doesnt-deserve-ussupport >, consultado em 18/09/2019.

Takenaka, Kiyoshi (2015), “Japão ameaça barrar fundos para Unesco por atrito com China sobre Massacre de Nanquim”. Reuters, 13 out. (Notícias mundiais). Disponível em <br.reuters.com/ article/worldNews/idBRKCN0S71JY20151013>, consultado em 18/09/2019.

The Guardian. (2016). "Japan halts Unesco funding following Nanjing massacre row". The Guardian, 14 out. (Agence France-Presse in Tokyo). Disponível em <www.theguardian.com/world/2016/oct/14/ japan-halts-unesco-funding-nanjing-massacrerow $>$, consultado em 18/09/2019.

UNESCO (2013a). Acta de la XIV Reunión del Mowlac, Comité Regional para América Latina y el Caribe - Programa Memoria del Mundo de la Unesco. Lima: Unesco.

UNESCO. (2013b), Documentary Collection - Life and Works of Ernesto Che Guevara: from the original manuscripts of its adolescence and youth to the campaign diary in Bolivia. Paris: Unesco.

UNESCO (2014). The War of the Triple Alliance: Iconographic and Cartographic presentations. Rio de Janeiro: Unesco.

UNESCO. (2002), Diretrizes para a salvaguarda do patrimônio documental. Paris: Unesco.

UNESCO. (2004), A Unesco no Brasil: consolidando compromissos. Brasília: Unesco.

UNESCO. (2008), To be or not to be remembered? The greatest challenges for the Memory of the World. Canberra: Unesco.

UNESCO. (2009). Candidatura Fundo Guerra do Paraguai. Rio de Janeiro: Unesco.

UNESCO. (2012), Memory of the World. The treasures that record our history from $1700 \mathrm{BC}$ to the present day. Paris: Unesco.

UNESCO. (2015). Documents of Nanjing Massacre. Paris: Unesco.

UNESCO. (2015b). 12th Meeting of the International Advisory Committee of The Memory of the World Programme. Abu Dhabi: Unesco. 


\section{GESTÁO CONFLITIVA DE MEMÓRIAS DOCUMENTAIS PELA UNESCO}

\section{Hilário Figueiredo Pereira Filho}

Palavras-chave: Gestão; Memória; Documentos; Unesco.

A partir do programa Memória do Mundo (MOW), da Unesco, o artigo destaca três candidaturas que receberam o título internacional de patrimônio documental: "Vida e obra de Ernesto Che Guevara: dos manuscritos originais da adolescência e juventude aos diários de campanha da Bolívia"; "Documentos do Massacre de Nanquim"; e "A Guerra da Tríplice Aliança: representaçóes iconográficas e cartográficas". Além de problematizar os argumentos mobilizados na construção dos dossiês, sublinharemos as consequências do reconhecimento concedido às propostas enquanto patrimônio da humanidade. Nossa hipótese é de que o Memória do Mundo explicita uma das facetas que configuram a Unesco: a conflituosa disputa de visôes, interesses e projetos entre os Estadosmembros dessa agência da Organização das Nações Unidas (ONU).

\section{CONFLICT MANAGEMENT OF DOCUMENTARY MEMORIES BY UNESCO}

\section{Hilário Figueiredo Pereira Filho}

Key words: Management; Memory; Documents; Unesco.

Based Unesco's Memory of the World (MOW) Program, this article highlights three applications that received the international title of documentary heritage: "Life and work of Ernesto Che Guevara: from original adolescent and youth manuscripts to Bolivian campaign diaries"; "Nanjing Massacre Documents"; and "The Triple Alliance War: Iconographic and Cartographic Representations". In addition to problematizing the arguments mobilized in the construction of each dossier, we will underline the consequences of the the recognition granted to these proposals as a humanity heritage. Our hypothesis is that the Memory of the World explains one of the facets that make up Unesco: the conflicting dispute of visions, interests and projects between the member states of this United Nations (UN) agency.

\section{GESTION CONFLICTUELLE DE MEMOIRES DOCUMENTAIRES PAR L'UNESCO}

\section{Hilário Figueiredo Pereira Filho}

Mots-clés: gestion; mémoire; documents; Unesco.

L'article met en évidence trois candidatures qui ont reçu le titre international de patrimoine documentaire dans le cadre du programme Mémoire du monde (MOW) de l'Unesco: La vie et l'ouvre d'Ernesto Che Guevara: des manuscrits originaux de l'adolescence et de la jeunesse aux journaux de campagne boliviens ; Documents du massacre de Nanjing; et $L a$ guerre de la triple alliance: représentations iconographiques et cartographiques. Le travail analyse les arguments mis en avant dans la construction des dossiers ainsi que les conséquences de la reconnaissance de patrimoine de l'humanité. Nous posons l'hypothèse que le programme Mémoire du monde reflète l'une des facettes de l'Unesco: la situation conflictuelle de visions, d'intérêts et de projets entre les États membres qui composent cette agence des Nations Unies (ONU). 